\title{
Seismic Behavior of a Newly Developed Base Isolation System for Houses
}

\author{
Bujar Myslimaj $^{1}$, Mitsumasa Midorikawa ${ }^{2}$, Masanori Iiba $^{3}$ and Masayoshi Ikenaga ${ }^{4}$ \\ ${ }^{1}$ Research Fellow, Department of Civil Engineering, McMaster University, Ontario, Canada \\ ${ }^{2}$ Research Director, Building Research Institute, Tsukuba, Japan \\ ${ }^{3}$ Senior Researcher, Building Research Institute, Tsukuba, Japan \\ ${ }^{4}$ Senior Researcher, Oiles Corporation, Tokyo, Japan
}

\begin{abstract}
The good performance of seismically isolated structures during the 1995 Kobe earthquake persuaded structural engineers, isolator manufacturers and housing construction companies to undertake a cooperative research project to investigate the possibility of introducing the seismic isolation technology in Japan's private housing sector. As a part of this project, in this study, the seismic performance of a recently developed Friction Pendulum System (FPS) for houses is presented. In order to verify its behavior under recorded earthquake ground motions, 3-dimensional shaking table tests were conducted. A three-dimensional nonlinear model was used to simulate the experimentally recorded acceleration and displacement response. Experimental results showed that the FPS significantly reduced the acceleration response at both moderate and strong levels of input ground motion. The analytical model used in this study satisfactorily predicted the experimentally recorded acceleration and displacement response time histories.
\end{abstract}

Keywords: seismic isolation; friction pendulum system; houses; 3-D shaking table tests; numerical simulation

\section{Introduction}

Kobe earthquake of January 17, 1995 severely hit one of the most populated urban areas of Japan, unfortunately located very close to the fault rupture area It was one of the worst natural disasters that Japan experienced in the second half of the $20^{\text {th }}$ century. The earthquake caused severe building damage and left thousands of people without shelter. Scientists and engineers involved in earthquake-related disciplines were shocked by the damage, deaths and injuries that resulted from this earthquake. As a result, important questions were raised about earthquake preparedness, disaster response, seismic design, upgrading of earthquake-resistant structures and introduction of new technologies, which can assure high safety levels against destructive earthquakes (Yamanouchi et al., 1997; Iiba et al., 1998).

The high concentration of damage in conventionally built residences (Building Research Institute, 1996) and the good performance of seismically isolated structures during this destructive earthquake (The Building Center of Japan, 1995) persuaded structural engineers, earthquake engineering researchers, isolator manufac-

Contact Author: Bujar Myslimaj, Research Fellow, Department of Civil Engineering, McMaster University 1280 Main Street West, Hamilton, Ontario, Canada L8S 4L7

Tel: +1-905-525-9140 Ext. 22044 Fax: +1-905-529-9688 e-mail: bujar@mcmaster.ca

(Received April 10, 2002; accepted September 5, 2002) turers and housing construction companies to undertake a cooperative research project to investigate the possibility of introducing seismically isolated structures in Japan's private housing sector. In order to achieve the required performance for the isolators and base-isolated residences, isolators' manufacturers were focused on the development of new types of devices. Based on the fundamental concepts used for developing each of them, they can be grouped in three systems: (a) Rubber bearing system, (b) Sliding system and (c) Rolling system. Details of the fundamental characteristics for each of the newly developed isolators and the outline of the shaking table tests performed are given elsewhere (Iiba et al., 2000). In this study, the focus is put on one of the isolators belonging to the group (b). Its fundamental characteristics are briefly discussed in the following section.

\section{Characteristics of the Newly-developed Isolator}

The recently developed friction pendulum system (FPS) for houses, shown schematically in Figure 1, is a compact frictional isolation system that combines a sliding action and a restoring force by geometry. Differently from the previously devised FPS, usually with an articulated slider moving on a spherical surface, the isolation device presented in this study has a sliding cylinder that moves on two coated spherical surfaces. Both sides of the sliding cylinder that are in contact with the spherical surfaces are coated with a low-friction composite material (Teflon). As the slider moves over the spherical surfaces, it causes the 
supported mass (weight) to rise, providing thus the restoring force for the system. Friction between the sliding cylinder and the spherical surfaces generates damping in the isolator. The effective stiffness of the isolator and the isolation period of the system are controlled by the radius of curvature of the concave surfaces. Normally, the coefficient of friction $\mu$ depends on the vertical stress in the isolator and sliding velocity, but taking into account the relatively low vertical stress in case of houses and high sliding velocity, the influence of the above factors on $\mu$ could be considered negligible for practical purposes. A typical $\mu$-value for the FPS presented in this study could be 0.04 . In Table 1 are summarized the fundamental characteristics of the FPS.

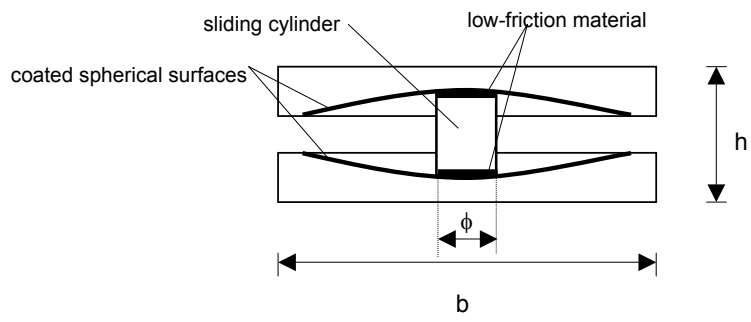

Fig.1. Schematic Drawing of the FPS

Table 1. Characteristics of the FPS

\begin{tabular}{l|c}
\hline $\mathrm{b}(\mathrm{mm})$ & 450 \\
$\mathrm{~h}(\mathrm{~mm})$ & 97 \\
$\phi(\mathrm{mm})$ & 80 \\
Load carrying capacity ( tf $)$ & 4.0 \\
Allowable displacement $(\mathrm{mm})$ & \pm 340 \\
Natural period $(\mathrm{sec})$ & 2.8 \\
Coefficient of friction $\mu$ & $0.02-0.05$ \\
\hline
\end{tabular}

The extremely simple mechanical modeling of the FPS makes it very attractive. However its simplicity is associated with the main disadvantage of the system. It is essentially a one-parameter system, and that parameter is controlled by the radius of the concave surface. In order for the various articulated surfaces to slide together all surfaces have to be spherical, resulting thus to a linear nature of the restoring force characteristic over the entire range of displacement.

\section{Outline of the Shaking Table Tests Performed}

In order to verify the FPS behavior under recorded earthquake ground motions, 3-dimensional shaking table tests were conducted. Tests were performed on a large-scale three-dimensional shaking table recently installed at the Public Work Research Institute of Ministry of Construction (PWRI, 1997). This shaking table is specially designed for simulating earthquake ground motions of the same intensity as those ones recorded during the Northridge Earthquake of January 17, 1994 or Kobe Earthquake of January 17, 1995.

The experimental setup is shown in Figure 2. It was used for testing the base-isolation system under one-, two- and three-directional earthquake excitations, providing thus the experimental data base necessary for the investigation of the effect of bi-directional and vertical earthquake motions on the characteristics of the FPS, as well as the effect of mass eccentricity on the response of the system. In Figure 3 is shown schematically how the experimental setup presented in Figure 2 was rearranged in order to create various conditions of mass/weight distribution in the system, i.e. balanced weight (top), unbalanced weight Case 1 (middle) and unbalanced weight Case 2 (bottom).

The input-output for the experimental setup shown in Figure 2 was monitored through 50 channels. As it is shown in the figure, accelerometers (strain-gauge type), velocity transducers (servo type) and displacement transducers (servo type, reel type, and laser type) were installed on the specimen.

Strong ground motions recorded during the El Centro Earthquake of 1940 and Kobe Earthquake of January 17, 1995 (JMA Kobe Station record) were used as input motions at the shaking table. Based on the peak ground velocity value observed in each record, the input earthquake waves were proportionally adjusted to various intensity levels. The following correspondence between the horizontal components of the recorded motions and the geometrical axes of the specimen (see Figure 2) was applied: $\mathrm{EW} \rightarrow \mathrm{X}$ and $\mathrm{NS} \rightarrow \mathrm{Y}$. In addition, in order to see the effect of vertical component of earthquake ground motion on the restoring force characteristic of the FPS, a special case of three-directional earthquake excitation was also considered, where only the vertical component of input motion was doubled.

In order to investigate the effect of bi-directional and vertical earthquake ground motion on dynamic response characteristics of the FPS, one-directional $(\mathrm{X}, \mathrm{Y})$, bi-directional $(\mathrm{XY}, \mathrm{YZ})$ and three-directional (XYZ, XYZ2) earthquake excitations (El Centro 1940, Kobe JMA 1995) were applied as input motions to the shaking table. The above shown XYZ2 symbol corresponds to the special case of a three-directional excitation, where the vertical component only was doubled.

\section{Results of the Tests and Discussion}

An experimental database covering all the series of tests mentioned above is already created and is being analyzed, with the purpose of investigating: a) the effectiveness of the FPS, b) the effect of bi-directional input ground motion, c) the effect of vertical ground motion and d) the effect of mass eccentricity.

\section{Effectiveness of the FPS}

In Figure 4 are shown the input and response acceleration time histories for El Centro (a) and Kobe JMA ground motion (b), adjusted to a peak ground velocity $(\mathrm{PGV})$ of $50 \mathrm{~cm} / \mathrm{s}$. Both the input and response correspond to the one-directional test in the $\mathrm{Y}$ direction and are observed at the center of the shaking table and the specimen, respectively. For both input ground motions a significant reduction in the acceleration 
response can be noticed. The ratio of peak response acceleration $\boldsymbol{A r}$, to peak input acceleration $\boldsymbol{A} \boldsymbol{i}$ for the two cases shown in Figure 4 (a) and (b) resulted to be 0.26 and 0.21 , respectively. It is important to note here that the beneficial effect of the FPS in remarkably reducing the acceleration response of the super-structure is basically achieved at the expense of a considerable displacement response that should be treated by the designers with special attention. In each FPS design, the designer should clearly specify the peak displacement limits of the system in accordance with the performance and serviceability requirements for a house.
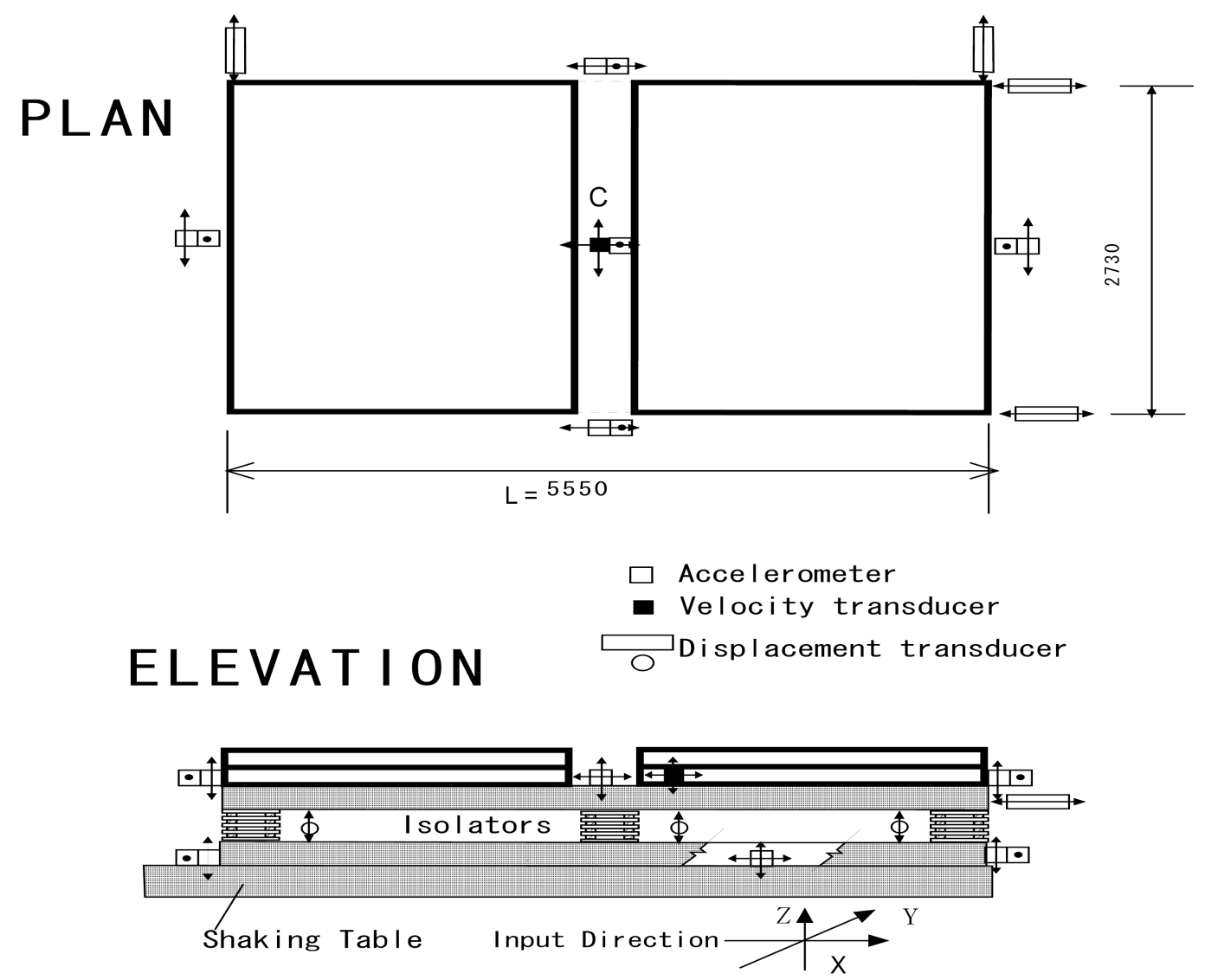

Fig.2. Experimental Setup Used for Testing the FPS

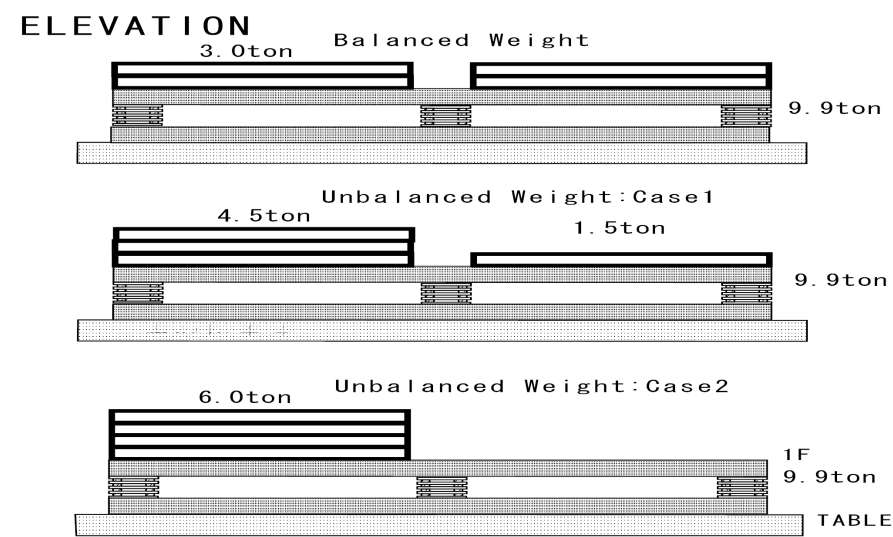

Fig.3. Three Patterns of Weight Distribution in the System 
The $\boldsymbol{A r} / \boldsymbol{A i}$ ratio depends on the input motion intensity. This can be clearly noticed from the plots shown in Figure 5, which represent the $\boldsymbol{A r} / \boldsymbol{A i}$ - PGV relation for both $\mathrm{X}$ and $\mathrm{Y}$ reference axis of the system subjected to a three-directional input motion. As the input motion intensity increases from 10 to $25 \mathrm{~cm} / \mathrm{s}$ the $\boldsymbol{A r} / \boldsymbol{A} \boldsymbol{i}$ ratio drops remarkably from 0.75 level to less than 0.50 , remaining after that almost unchanged even though the $\mathrm{PGV}$ increases up to $50 \mathrm{~cm} / \mathrm{s}$.

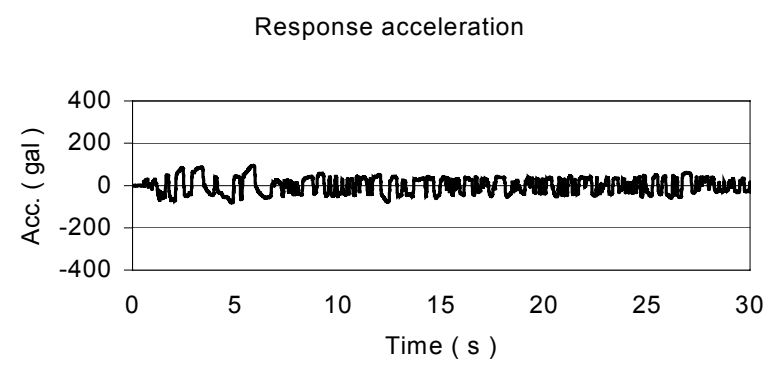

Input acceleration

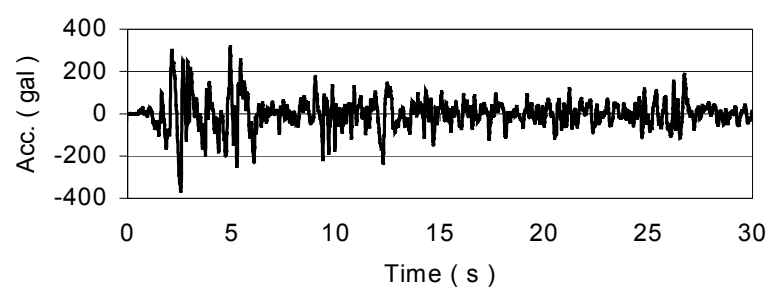

(a) El Centro
Effect of bi-directional and vertical ground motion

In order to investigate the effect of bi-directional and vertical earthquake ground motion on dynamic response characteristics of newly developed base-isolation system for houses, one-directional (X, Y), bi-directional (XY, YZ) and three-directional (XYZ, XYZ2) earthquake excitations (El Centro 1940, Kobe JMA 1995) were applied as input motions to the shaking table.

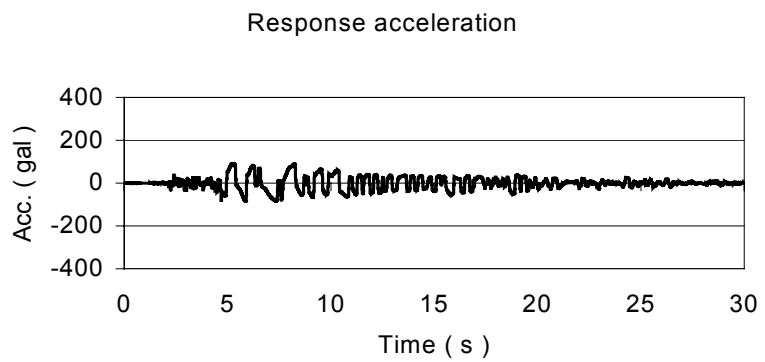

Input acceleration

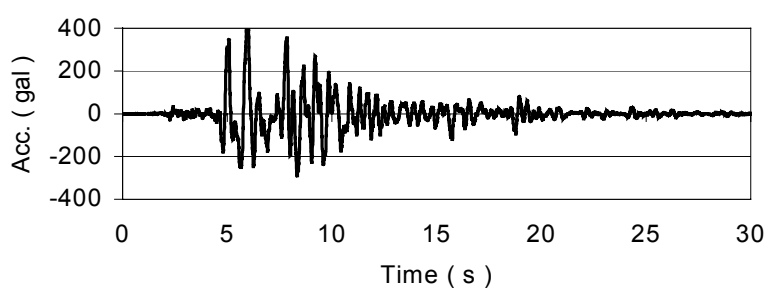

(b) Kobe JMA

Fig.4. The Input and Response Acceleration Time Histories for El Centro and Kobe JMA Ground Motions Adjusted to a Peak Ground Velocity of $50 \mathrm{~cm} / \mathrm{s}$
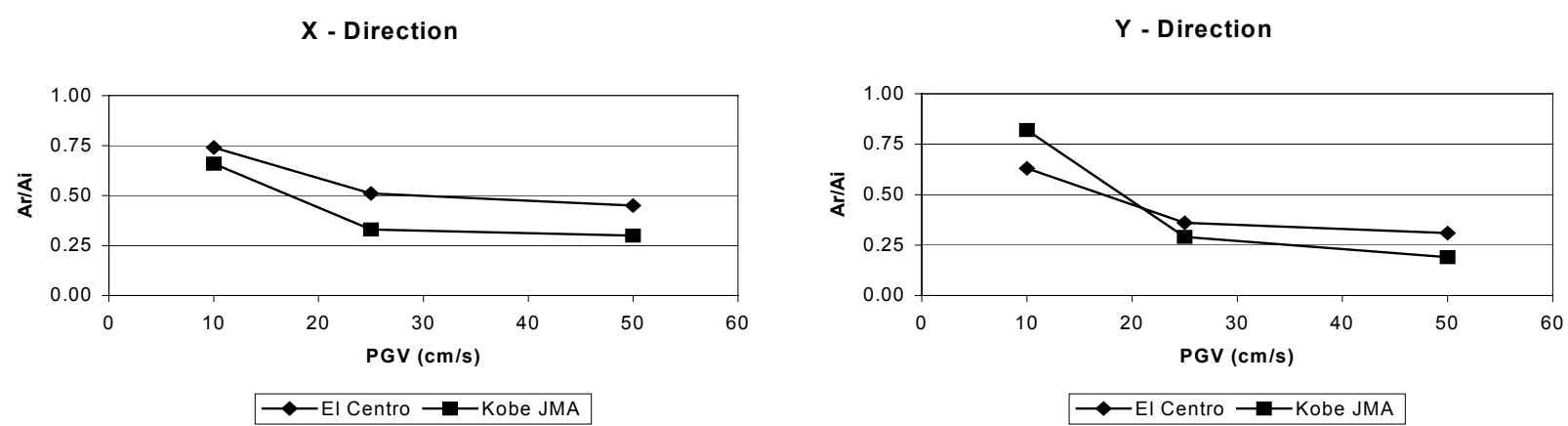

Fig.5. The $\boldsymbol{A r} / \boldsymbol{A i}$ - PGV Relation for Both X and Y Reference Axis of the System Subjected to Three-directional Input Motions Adjusted to Various Intensity Levels

In Figure 6 are shown displacement-shear force coefficient relations in Y-direction, for one-directional (Y) (a), bi-directional (XY) (b) and three-directional (XYZ2) (c) Kobe JMA input motion, adjusted to a peak ground velocity of $50 \mathrm{~cm} / \mathrm{s}$. Comparing first the hysteresis loops shown in Figures 6(a) and 6(b), no significant difference can be seen between them, although they correspond to one- and two-directional earthquake excitations. In case of three-directional excitation (Fig. 6(c)), a bit higher response acceleration compared to one- and two-directional excitation case has produced a slightly "fatter" hysteresis loop, 
demonstrating thus the way the vertical component of input motion is expected to affect the restoring force characteristics of newly-developed FPS for houses.

\section{Effect of mass-eccentricity}

Based on the experimental setup shown previously in Figure 3, series of tests were conducted with the purpose of investigating the effect of mass eccentricity on the response of FPS. Three patterns of weight distribution into the system (Figure 3) correspond to mass eccentricity ratios of $0,0.094$ and 0.188 , respectively (Inoue et al., 1999). It should be mentioned here that these mass eccentricity ratios represent the system's mass eccentricity in reference to the center of geometry C, normalized by L/2 (see Figure 2). During these tests, El Centro 1940 and Kobe JMA input motions were adjusted to the intensity levels of PGV $25 \mathrm{~cm} / \mathrm{s}$ and $50 \mathrm{~cm} / \mathrm{s}$.

In order to see at what extension the mass eccentric- ity could affect the displacement response of the FPS, the ratio PDHS/PDLS, where PDHS and PDLS represent respectively the Peak Displacement of the Heavier Side and the Peak Displacement of the Lighter Side, is plotted against mass eccentricity ratio (Figure 7). From both graphs shown in Figure 7 it can be noticed that, regardless of the input ground motion, the PDHS/PDLS increases as the mass eccentricity ratio increases. On average, for the mass eccentricity ratio of 0.188 the PDHS/PDLS results to be 1.15 . It can be further noticed that the PDHS/PDLS ratio is almost unaffected by the input motion intensity level. Since the FPS significantly reduces the acceleration response of the superstructure, as shown in previous sections, the expected stress increase due to mass-eccentricity is expected to be negligible from the engineering practice point of view.
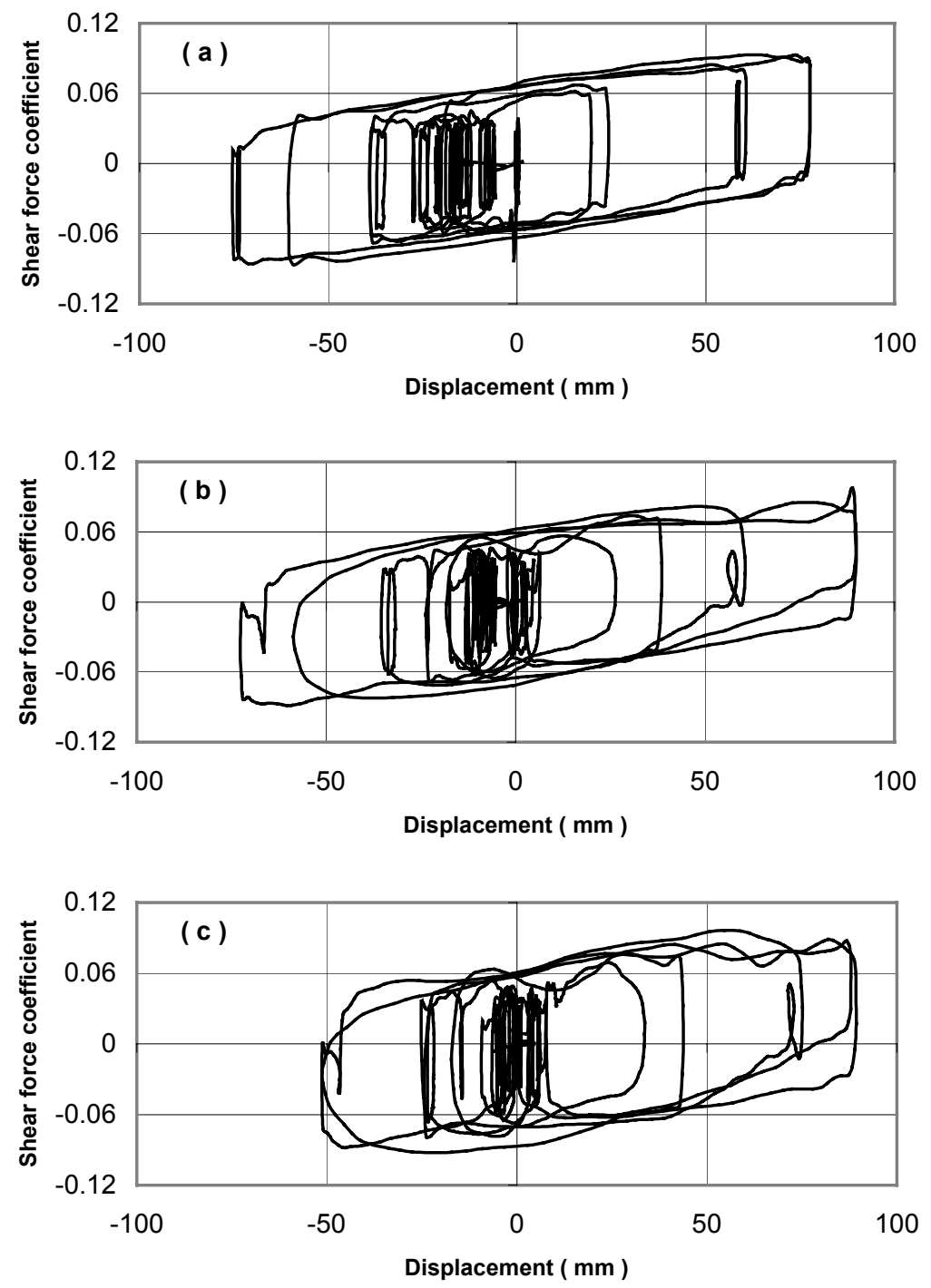

Fig.6. Displacement-Shear Force Coefficient Relation in Y-direction, for One- (a), Two- (b) and Three-directional (c) Kobe Input Motion Adjusted to a PGV of $50 \mathrm{~cm} / \mathrm{s}$ 
Analytical Simulation of the Recorded Response

While 3-dimensional shaking table tests provided a very necessary information for understanding the real dynamic behavior and performance of the newly developed base isolation system, in the design practice a reliable analytical tool is needed to predict the response of the system.

In this study, a three dimensional nonlinear model is used to simulate the experimentally recorded acceleration and displacement response time histories. As shown in Figure 8, it consists of a rigid slab supported by six three-dimensional springs along the
$P G V=25 \mathrm{~cm} / \mathrm{s}$

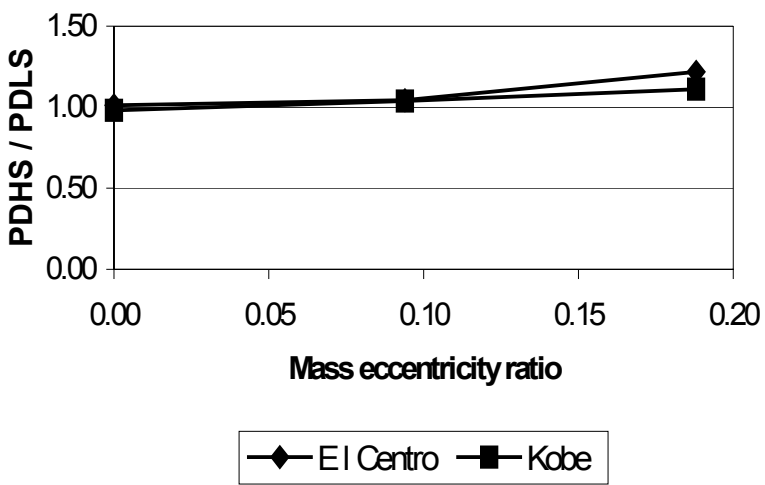

$P G V=50 \mathrm{~cm} / \mathrm{s}$

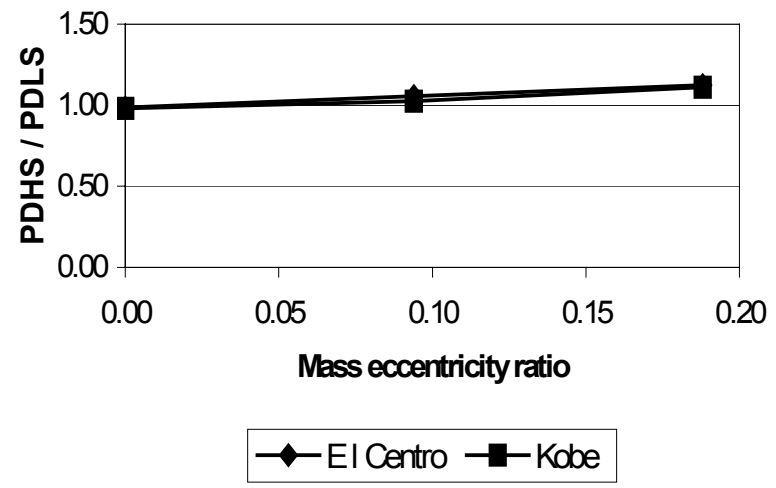

Fig.7. PDHS/PDLS versus Mass Eccentricity Ratio

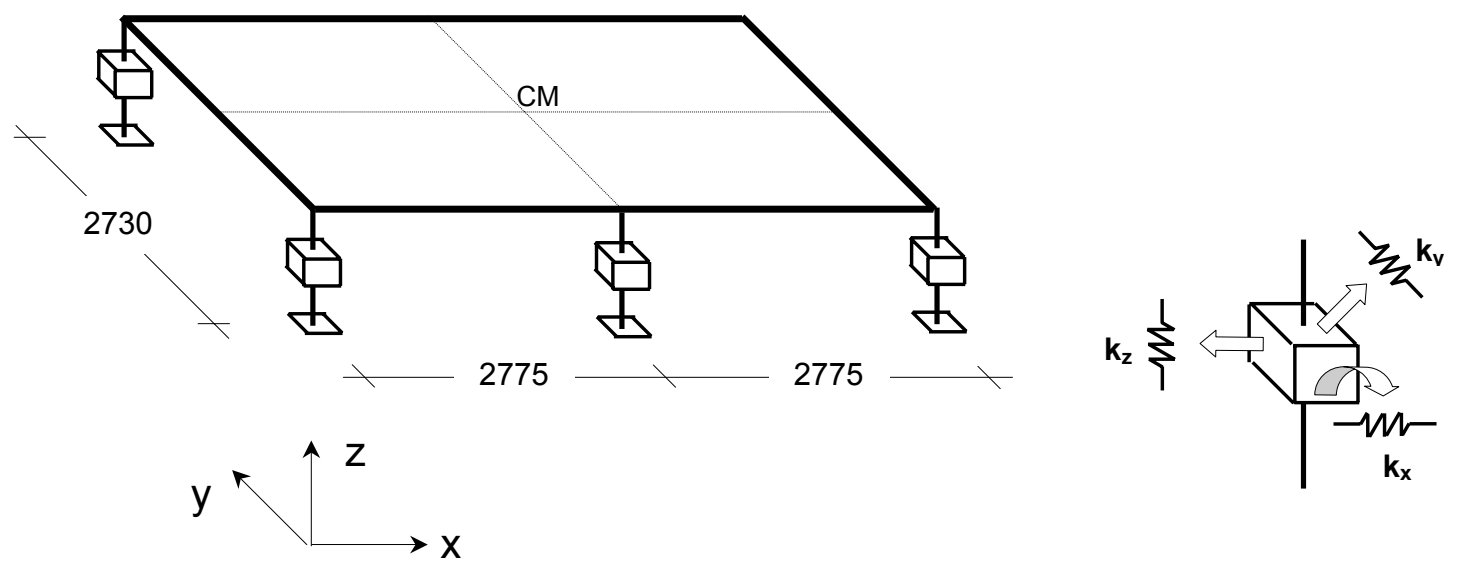

Fig.8. 3-dimensional Nonlinear Model Used in Analytical Simulation

perimeter of the slab. Each of the 3-D springs models a FPS isolator. As observed from cyclic loading tests on single FPS isolators, the restoring force characteristics for horizontal springs $\mathbf{k}_{\mathbf{x}}$ and $\mathbf{k}_{\mathbf{y}}$ can be satisfactorily modeled by a rigid-plastic type bilinear model. The high initial stiffness $\left(\mathrm{K}_{1}\right)$ before sliding occurs can be estimated as a multiple of post-yield stiffness $\mathrm{K}_{2}$, which can be accurately estimated or predicted based on the vertical load acting on the isolator (W) and the radius of curvature $\mathrm{R}$ of the spherical surface.

Assuming that the average vertical load on each isolator for the case of balanced weight (see Figure 3 ) is
$\mathrm{W}=16 / 6 \approx 2.7 \mathrm{tf}$, one can easily estimate $\mathrm{K}_{2}$ as $\mathrm{W} / \mathrm{R}=2.7 / 2$, i.e. $\mathrm{K}_{2}=1.35 \mathrm{tf} / \mathrm{m}$. This stiffness produces an isolated system period $\mathrm{T}=2 \pi\left(\mathrm{W} / \mathrm{gK}_{2}\right)^{1 / 2}=2 \pi(\mathrm{R} / \mathrm{g})^{1 / 2}$ $=2.84 \mathrm{sec}$. In order to assure sufficient enough rigidity in the system before sliding, the ratio $\mathrm{K}_{1} / \mathrm{K}_{2}$ was set at 1000 , that is assuming $\mathrm{K}_{1}=1350 \mathrm{tf} / \mathrm{m}$. Finally, using $\mu=0.04$ as a typical $\mu-$ value for the FPS presented in this study, one can determine the yield shear force in each isolator at sliding as $\mathrm{Q}_{\mathrm{y}}=\mu \mathrm{W}=0.108 \mathrm{tf}$. It should be noted here that $\mathrm{Q}_{\mathrm{y}}=0.108 \mathrm{tf}$ corresponds only to the case of the balanced weight distribution in the system. For the other cases of weight distribution shown in 
Figure 3, $\mathrm{Q}_{\mathrm{y}}$ is not any longer the same for each isolator.

First, the EW component of El Centro adjusted to a $\mathrm{PGV}$ of $50 \mathrm{~cm} / \mathrm{s}$ was used as input motion along the $\mathrm{X}$-axis. The acceleration and displacement response at $\mathrm{CM}$ in the $\mathrm{X}$ direction were then analytically simulated and compared with those recorded experimentally during the shake table tests. These results are shown in Figure 9, where a very good agreement between the analysis and experiment can be noticed.

In order to demonstrate further the simulation capabilities of the 3-D model, the NS component of El Centro adjusted to a $\mathrm{PGV}$ of $50 \mathrm{~cm} / \mathrm{s}$ was used as input motion along the Y-axis of the system having an eccentric weight distribution arranged according to the case 2 (see Figure 3). As it was mentioned above, for this case $Q_{y}$ for the pair of isolators on the heavier side is larger than that one of the pairs on the lighter side. This was taken into account in the modeling process by assigning different $\mathrm{Q}_{\mathrm{y}}$ to each isolator based on its location, i.e. vertical load share. Here, the focus was put on the acceleration and displacement response at the heavier and the lighter side of the slab. These results are shown in Figure 10. Here also, the satisfactory agreement between the analysis and experiment can be clearly noticed.

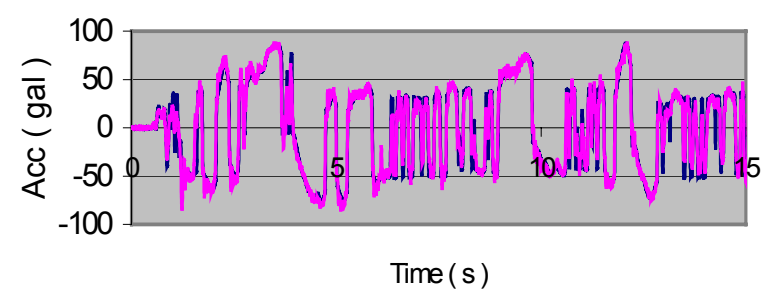

-Analysis - Experiment

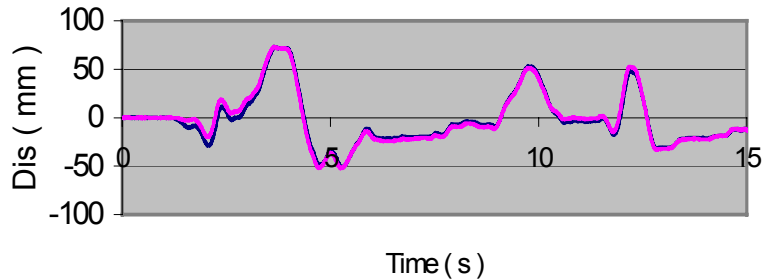

- Analysis —-Experiment

Fig.9. Compared Acceleration and Displacement Time Histories at CM

\section{Heavier side}

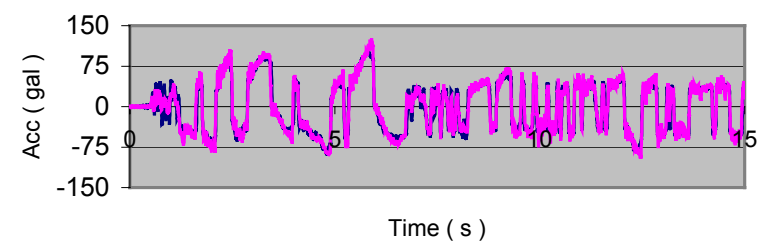

- Analysis —-Experiment

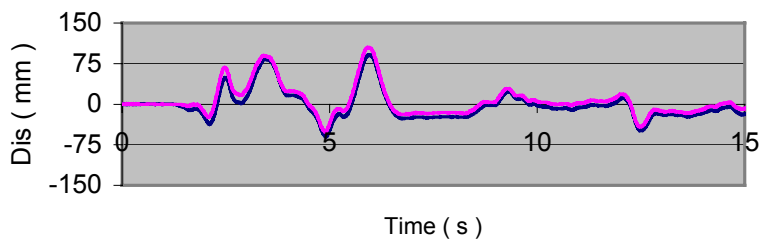

- Analysis —-Experiment

\section{Lighter side}
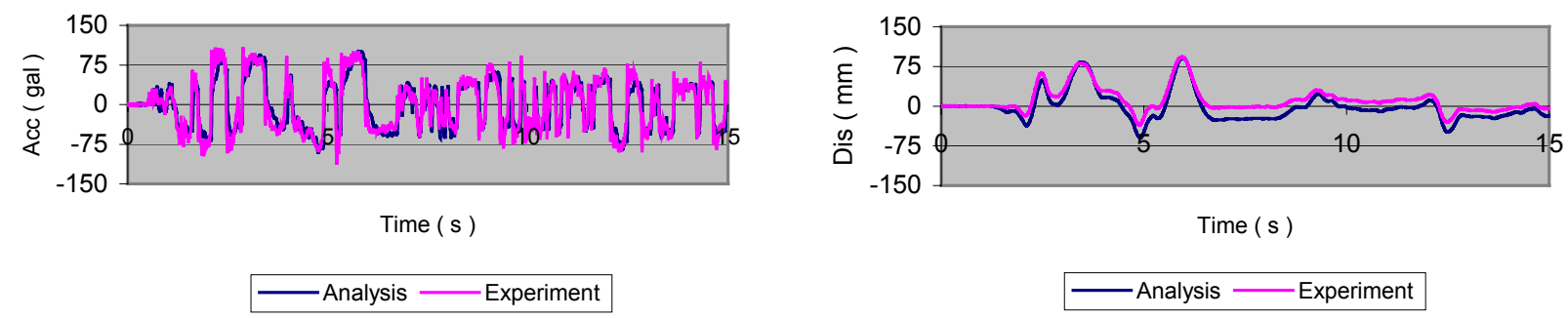

Fig.10. Compared Acceleration and Displacement Time Histories at Both Sides of a Mass-eccentric System 


\section{Conclusions}

Three-dimensional shaking table tests on a newly developed Friction Pendulum System (FPS) for houses were conducted. These tests were primarily designed to investigate the effectiveness of the FPS; the effect of bi-directional input ground motion; the effect of vertical ground motion and the effect of mass eccentricity. In addition to the tests, a three-dimensional nonlinear model was conceived and elaborated in order to simulate the experimentally recorded acceleration and displacement response. The most relevant observations made in the previous sections are summarized as follows:

1. The FPS reduced significantly the acceleration response at both moderate and strong levels of input ground motion. Depending on the input motion intensity, the ratio of peak response acceleration to peak input acceleration calculated from the experimental data resulted to be in the range of 0.2-0.5.

2. No significant difference could be observed between the results obtained by one- and two-directional earthquake excitations. The effect of vertical component of ground motion on the characteristics of FPS appears to be negligible.

3. Tests results indicated that for a mass eccentricity ratio of nearly $20 \%$, the ratio PDHS/PDLS could go up to 1.15 .

4. The analytical model conceived and elaborated in this study satisfactorily predicted the experimentally recorded acceleration and displacement response time histories.

\section{Acknowledgments}

The authors would like to express their sincere thanks to all the members of the committee on "Development of seismically isolated houses", the chairman of which is Mr. Shoichi Yamaguchi, president of Tokyo Kenchiku Structural Engineers, for providing data and valuable suggestions related to this study. The assistance of Dr. Keiichi Tamura and Mr. Takuo Azuma, respectively Head and Research Engineer of the Ground Vibration Division at the Earthquake Disaster Prevention Research Center of Public Work Research Institute in Tsukuba, in operating the large-scale three-dimensional shaking table is greatly appreciated.

\section{References}

1) Building Research Institute (1996) A survey report for building damages due to the 1995 Hyogo-ken Nanbu Earthquake. Building Research Institute, Ministry of Construction, Japan.

2) Iiba, M., Yamanouchi, H., Midorikawa, M., et al. (1998) Research on performance of base isolated houses. Proceedings of the Second World Conference on Structural Control (2WCSC), Vol. 2 1119-1126.

3) Iiba, M., Midorikawa, M., Yamanouchi, H., et al. (2000) Shaking table tests on performance of isolators for houses subjected to three dimensional earthquake motions. Proceedings of the 12-th World Conference on Earthquake Engineering. Paper No. 1765.

4) Inoue, K., Iiba, M., Myslimaj, B., et al. (1999) Three dimensional shaking table tests on seismic behavior of isolators for houses - Part 3: Effect of unbalanced weight on characteristics of isolators. In:
Summaries of Technical Papers of Annual Meeting of Architectural Institute of Japan; Vol. B-2: 745-746 (in Japanese).

5) Public Work Research Institute (1997) Large-scale three-dimensional shaking table. Public Work Research Institute, Ministry of Construction, Japan.

6) Yamanouchi H., Midorikawa M. and Iiba M. (1997) Research and development on base-isolation technologies for houses - A survey on the performance based evaluation of base-isolated houses and shaking table tests on model houses. Kenchiku Kenkyu Shiryo, No. 89, (in Japanese).

7) The Building Center of Japan (1995) Sheet of outlines for base-isolated buildings. The Building Letter, June-1995, 57-58 (in Japanese). 